\title{
Final Development and Test Preparation of the First 3.7 m Long Nb3Sn Quadrupole by LARP
}

\author{
G. Ambrosio, N. Andreev, M. Anerella, E. Barzi, B. Bingham, D. Bocian, B. Bordini, R. Bossert, L. Bottura,
} S. Caspi, G. Chlachidize, W. M. De Rapper, D. Dietderich, J. Escallier, H. Felice, P. Ferracin, A. Ghosh, A. Godeke, R. Hafalia, R. Hannaford, G. Jochen, V. V. Kashikhin, P. Kovach, M. Lamm, A. McInturff, J. Muratore, F. Nobrega, I. Novitsky, D. Orris, S. Peggs, E. Prebys, S. Prestemon, G. L. Sabbi, J. Schmalzle, C. Sylvester, M. Tartaglia, D. Turrioni, G. Velev, P. Wanderer, G. Whitson, G. Willering, and A. V. Zlobin

\begin{abstract}
The test of the first LARP (LHC Accelerator Research Program) Long Quadrupole is a significant milestone toward the development of $\mathrm{Nb}_{3} \mathrm{Sn}$ quadrupoles for LHC (Large Hadron Collider) Luminosity Upgrades.

These 3.7-m long magnets, scaled from the 1-m long Technological Quadrupoles, are used to develop our capabilities to fabricate and assemble $\mathrm{Nb}_{3} \mathrm{Sn}$ coils and structures with lengths comparable to accelerator magnet dimensions. The long quadruples have a target gradient of $200 \mathrm{~T} / \mathrm{m}$ in a $90-\mathrm{mm}$ aperture. Pre-stress and support are provided by an Al-shell-based structure pre-loaded using bladders and keys. The coils were fabricated at BNL and FNAL, the shell-based structure was designed and assembled at LBNL, the test is performed at FNAL.

In this paper we present the final steps of the development of the first model (LQS01), several upgrades to the test facility, the test results of witness cables, and the short sample limit.
\end{abstract}

Index Terms-LARP, long magnet, Nb3Sn, superconducting magnet.

\section{INTRODUCTION}

$\mathbf{T}$ HE U.S. LHC Accelerator Research Program (LARP) is developing $\mathrm{Nb}_{3} \mathrm{Sn}$ quadrupole magnets [1] for possible use in LHC luminosity upgrades. A crucial step in this development is to demonstrate that design features and fabrication technologies successfully implemented in short models can be applied to accelerator-size magnets. Preliminary steps in this direction have been taken by LARP with the Long Racetrack [2], and by Fermilab with the Long Mirror Magnet [3].

Manuscript received October 19, 2009. First published March 29, 2010; current version published May 28, 2010. This work was supported in part by the U.S. Department of Energy.

G. Ambrosio, N. Andreev, E. Barzi, D. Bocian, R. Bossert, G. Chlachidize, V. V. Kashikhin, M. Lamm, F. Nobrega, I. Novitsky, D. Orris, E. Prebys, C. Sylvester, M. Tartaglia, D. Turrioni, G. Velev, G. Whitson, and A. V. Zlobin are with Fermi National Accelerator Laboratory, Batavia, IL 60510 USA (e-mail: giorgioa@fnal.gov).

M. Anerella, J. Escallier, A. Ghosh, G. Jochen, P. Kovach, J. Muratore, S. Peggs, J. Schmalzle, and P. Wanderer are with Brookhaven National Laboratory, Upton, NY 11973 USA.

B. Bingham, S. Caspi, D. Dietderich, H. Felice, P. Ferracin, A. Godeke, R. Hafalia, R. Hannaford, A. McInturff, S. Prestemon, and G. L. Sabbi are with Lawrence Berkeley National Laboratory, Berkeley, CA 94720 USA.

B. Bordini, L. Bottura, W. M. De Rapper, and G. Willering are with CERN, CH-1211 Geneva 23, Switzerland.

Color versions of one or more of the figures in this paper are available online at http://ieeexplore.ieee.org.

Digital Object Identifier 10.1109/TASC.2010.2040471

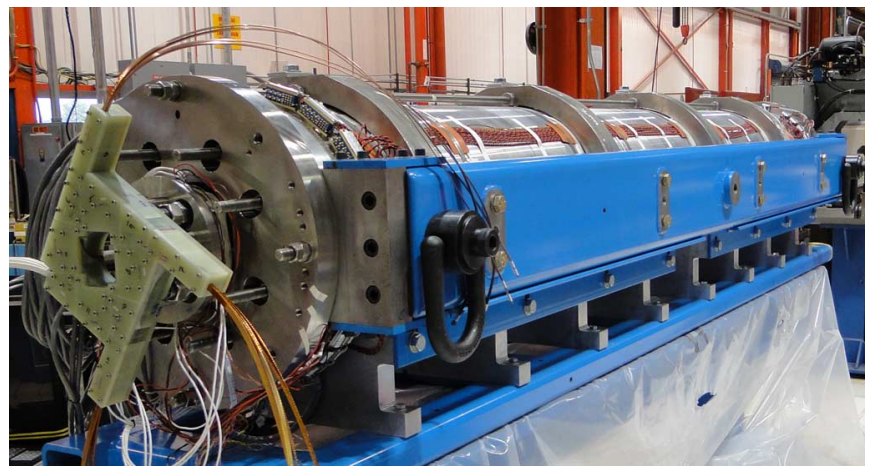

Fig. 1. LQS01 during the preparation of coil interconnections. Bottom raft and side beams are used for handling and will be removed before test.

Whereas these magnets aimed at testing long coils, LARP is presently preparing the test of a 3.7-m Long Quadrupole (LQ) that, although missing some accelerator-magnet features, aims at demonstrating that $\mathrm{Nb}_{3} \mathrm{Sn}$ can be used for the next generation of accelerator magnets. The LQ has a $90-\mathrm{mm}$ aperture, two-layer shell-type coils and a target gradient of $200 \mathrm{~T} / \mathrm{m}$. The design is based on the 1-m LARP Technological Quadrupoles (TQ) [4]-[6].

The coil design and fabrication technology is based on the TQ coils with some new features (reaction and impregnation in single-coil fixtures, using mica during the heat treatment, and gaps between pole parts) introduced during the LQ practice coils development. The LQ coils and structure are instrumented with a large number of voltage taps ( 20 per coil) and strain gauges stations (4 per coil, and 10 on the shell) consisting of two full bridges each, and two half bridges on each rod [7].

The quench protection is quite challenging because LQ has the same coil design and conductor, with only $46 \%$ copper, of the second-generation TQ magnets, together with four times larger stored energy. Therefore ad-hoc protection heaters were designed and installed also on the coil inner layers; and the test facility had several upgrades in preparation for the LQ test. Further details about the Long Quadrupole design can be found in [8].

Four readiness reviews (structure, coils, assembly, and test preparation) were performed at different stages of the LQS01 development. All reviews were successfully passed and LQS01 test is schedule to start around the beginning of November (Fig. 1). 


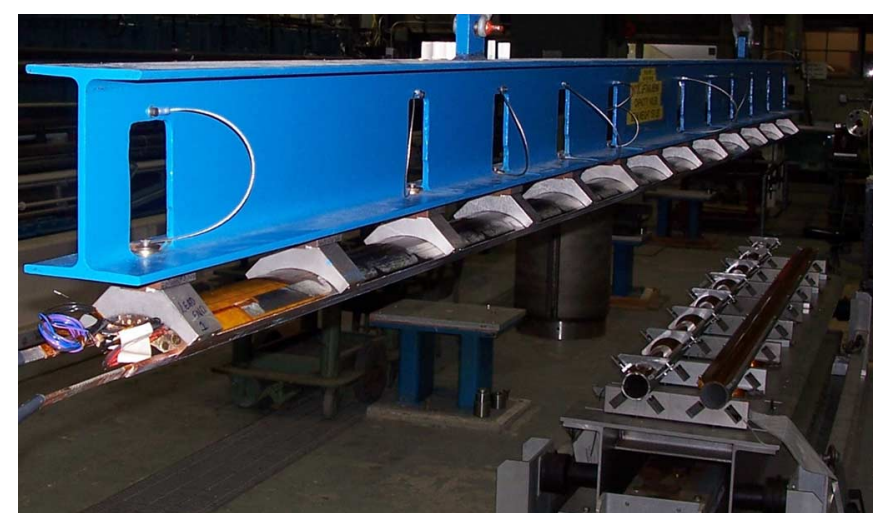

Fig. 2. LQ coil after impregnation being moved to the shipping mandrel.

LQS01 short sample limit at $4.3 / 1.9 \mathrm{~K}$ is $13.9 / 15.3 \mathrm{kA}$ (peak field $=12.4 / 13.6 \mathrm{~T}$; gradient $=242 / 265 \mathrm{~T} / \mathrm{m}$; stored energy $=473 / 570 \mathrm{~kJ} / \mathrm{m})$.

\section{COIL FABRICATION}

\section{A. Coil Design and Fabrication Process}

The coils of the long quadrupole consist of two layers, wound without interlayer splice. The cable $(10.077 \mathrm{~mm}$ wide, $1.26 \mathrm{~mm}$ think, with $1 \mathrm{deg}$. Keystone angle) is made of 27 strands $(0.7$ $\mathrm{mm}$ diameter) and insulated with a $0.1 \mathrm{~mm}$ thick sleeve made of S-glass reinforced by a minimal amount of palmitic acid on the cable edges. The first LQ practice coil has copper strands, all following LQ coils have RRP 54/61 (Restack Rod Process strands with $54 \mathrm{Nb}_{3} \mathrm{Sn}$ subelements) made by Oxford Superconducting Technology. Cabling and application of the insulation are performed at LBNL for all LQ coils. These two processes take almost three weeks.

After winding, each coil layer is cured under pressure in a precise closed cavity mold at $150^{\circ} \mathrm{C}$ for 30 minutes. Voltage taps (bronze flags) are inserted through a cut-out in the cable insulation during the winding. Winding and curing, which take three weeks, are performed at Fermilab.

The coils are subsequently reacted in a gas-tight fixture in a gas-tight oven. Independent argon lines are used for flushing and keeping a small over pressure in both the reaction fixture and the oven. The reaction cycle $\left(72 \mathrm{hrs}\right.$ at $210^{\circ} \mathrm{C} ; 48 \mathrm{hrs}$ at $400^{\circ} \mathrm{C} ; 48$ hrs at $640^{\circ} \mathrm{C}$ ) is automatically controlled in order to keep the whole fixture within $+/-2^{\circ} \mathrm{C}$ of the target temperature during plateaus. The reaction process is performed at Fermilab (the first three coils, and subsequent even-number coils) and at BNL (odd-number coils starting with coil \#05). The whole process, including preparation for the reaction and disassembling of the fixture after reaction, takes five weeks.

The coils are vacuum impregnated using CTD-101K in the same laboratory where they were heat treated. The impregnation fixtures have the same design as the reaction fixtures allowing for a smooth transition of the coil from one fixture to the other while the coil is prepared for the impregnation (adding instrumentation traces, part of the ground insulation and instrumentation). This process, including clean-up after impregnation, takes four weeks (Fig. 2).
The final part of the instrumentation (including strain gauges, spot heater, wiring, connectors, and final electrical check-out) is performed at LBNL where the magnets are assembled. This process takes two weeks.

The coils are shipped on a rigid shipping mandrel anchored on a steel beam connected through shock-absorbers to a reinforced crate. Shipment is performed by dedicated truck so that the crate will be handled only at the points of loading and unloading by LARP personnel. Coil preparation for shipment and the actual shipment take two weeks.

\section{B. Practice Coils}

During the fabrication of the first two practice coils some issues were found and addressed by modification of the reaction fixture and by introducing mica [9]. Practice coil \#03 showed a longitudinal tension $(\sim 600 \mathrm{Kg})$ applied by the pole to the inner layer (IL). The analysis presented in [9] led to the introduction of small gaps between pole parts in order to avoid the development of this tension during the reaction process. Practice coils \#04 and \#05 were used to test and fine tune this solution. The target of this optimization was to have no tension and no gaps after the heat treatment. The procedures used for introducing the gaps during winding, without modifications to tooling and parts, cause the outer layer (OL) gaps to depend on the IL gaps with an uncertainty due to friction. The solution adopted (IL gaps $=5.7 \mathrm{~mm} ; 4.9<$ OL gaps $<3.6 \mathrm{~mm}$ ) reflects this dependence.

\section{Production Coils}

Throughout the fabrication of the first five production coils (\#06-\#10) discrepancies reported during winding and curing decreased from eight to one. None of these discrepancies was severe (i.e. causing permanent damage or irregularity); some of them were moderate such as damages to the insulation (occurred during insulation application, winding, or curing) that can be fixed.

Three severe discrepancies occurred during reaction or impregnation. These discrepancies and remedies implemented are described below.

First, coil \#06 showed some dry areas after impregnation. These areas, mostly on the OL, started as small patches in the center of the coil, and became larger close to the lead end. This end is the last part of the coil to be impregnated since epoxy is injected from the return end with the coil resting on a 15-deg inclined beam. Inspection of the surface and transverse cuts of coil $\# 05$, which showed a small dry area, revealed that it is limited to the coil surface. On the top of the OL coil a $0.125 \mathrm{~mm}$ thick layer of S2-glass insulation is set between two Kapton layers (the instrumentation trace and a foil, covered with mold-release, which is removed after impregnation in order to leave space for the ground insulation). Epoxy seems to propagate slower in this Kapton sandwich than through the rest of the coil. A previously impregnated practice coil that had a ceramic cloth instead of the S2-glass didn't show any dry areas. Nonetheless the problem was solved by letting the latter coils rest for a minimum of 12 hours, after impregnation, at $60^{\circ} \mathrm{C}$ with atmospheric pressure pushing on the epoxy. A second impregnation, previously tested on practice coil \#05, was used to fix coil-\#06 dry spots. This 
process filled all dry areas, leaving a very smooth OL surface, a minimal (few microns) growth of the coil cross-section, and a few small bubbles on the surface of the lead end IL.

Second, during the $640^{\circ} \mathrm{C}$ plateau of coil \#07 there was a short interruption of argon flow caused by a trip of the circuit breaker powering the argon supply solenoid valves. Pressure in the reaction fixture and in the oven drifted down over approximately $1 \mathrm{hr}$, and about $1 / 2$ hour passed with no pressure before flow was resumed. During the same heat treatment the oven shut down completely, after approximately 40 hours at $640^{\circ} \mathrm{C}$, due to a site wide power failure. Argon flow was restarted manually after approximately 3 hours when temperature was down to $555^{\circ} \mathrm{C}$. Power was restored after a total of approximately 5.5 hours when temperature was down to $520^{\circ} \mathrm{C}$. The oven was heated back to $640^{\circ} \mathrm{C}$ and held for an additional 8 hours to complete the cycle. In addition, argon flow terminated during cool-down at $\sim 240^{\circ} \mathrm{C}$ because the argon container ran out unexpectedly overnight. Solenoid valves controlling argon flow were removed after this HT. All witness samples performed well.

Third, after the impregnation of coil \#09 epoxy was stuck to a midplane shim, in a few areas, and cables were exposed when the shim was removed. The mold-release was changed after this problem, and the exposed surface of the coil was fixed by using a glass cloth and painting a thin layer of Stycast 2850FT. The impregnation fixture was reassembled and tightened around the coil during the $24 \mathrm{hrs}$ curing of Stycast at room temperature. CMM measurement of a repaired cross-section showed a very small difference with respect to undamaged cross-sections.

During the LQS01 Coil Readiness Review all discrepancies and possible impact on magnet performance were analysed and discussed. It was decided to use all of the first four production coils (\#06 to \#09). The decision was motivated by the following factors: assessment of the good quality of the repairs and of their successful implementation in shorter coils (\#06 and \#09); negligible impact of discrepancies on witness samples (\#07); impact on the schedule (one month delay if coil \#10 was needed, 3 months for coil \#11). Since similar discrepancies may occur in any $\mathrm{Nb}_{3} \mathrm{Sn}$ coil production series this test may give us the opportunity to understand whether such discrepancies can be safely addressed.

\section{SUPPORT StRUCTURE AND LQS01 ASSEMBLY}

The LQS mechanical structure is based on TQS [5] providing support and pre-stress by an aluminum shell pre-loaded with bladders and keys. The ends are supported and pre-stressed by thick end plates connected by four stainless steel rods pre-tensioned at room temperature. Several changes have been introduced in the LQ structure, with respect to the TQS structure, in order to facilitate the assembly, add some alignment features (from shell to pads- the parts in contact with the coils), and provide a uniform pre-stress taking into account the increased length [10].

LQS01 was assembled at LBNL after testing the structure with aluminum dummy coils. The iron pads were first bolted around the coils. Subsequently the coil-pack was inserted in the shell-yoke sub-assembly and pre-loaded using water-pres-
TABLE I

LQS01 MEASUREd $( \pm 1 \sigma)$ STRAIN AND STRESS IN SHELL, COIL WINDING POLES, AND AXIAL RODS

\begin{tabular}{lcccc}
\hline \hline $293 \mathrm{~K}$ & $\varepsilon_{\mathrm{y}}(\mu$ strain $)$ & $\varepsilon_{\mathrm{z}}(\mu$ strain $)$ & $\sigma_{\mathrm{y}}(\mathrm{MPa})$ & $\sigma_{\mathrm{z}}(\mathrm{MPa})$ \\
\hline Shell meas. & $+451 \pm 113$ & $-113 \pm 108$ & $+33 \pm 8$ & $+3 \pm 7$ \\
\hline Pole meas. & $-125 \pm 71$ & $+135 \pm 119$ & $-12 \pm 11$ & $+14 \pm 17$ \\
\hline Rod meas. & $\mathrm{n} / \mathrm{a}$ & $+310 \pm 18$ & $\mathrm{n} / \mathrm{a}$ & $+60 \pm 3$ \\
\hline \hline
\end{tabular}

surized bladders. 56 strain gauges were monitored during the loading [11]. The data are shown in Table I.

The shell and the axial rods were pre-loaded respectively to +33 MPa of azimuthal stress and +60 MPa of axial stress, corresponding to the room temperature target values computed by the model. The coil pre-load was measured to be $-12 \mathrm{MPa}$, a value below the expectations and currently under investigation.

\section{Test PReParation}

LQS01 magnet is going to be tested at Fermilab's Vertical Magnet Test Facility (VMTF) [12]. Some VMTF subsystems were modified in preparation to LQS01 magnet test in order to improve magnet protection or quality of test data.

The magnet protection system was modified to accommodate the large number of protection heaters in LQS01 magnet. Each coil of LQ is equipped with 4 protection heaters, two per layer, and one spot heater [8]. The stainless steel heaters with heating sections (narrow parts with increased resistance) are photo-etched on a Kapton foil (trace) potted with the coil. The re-designed magnet protection system includes four heater firing units, each operating four protection heaters connected in parallel. Two heater firing units are used for spot heaters. Heaters and heater firing units were successfully tested, above operating conditions at Fermilab, with practice coil \#05 in a liquid nitrogen bath.

Transient magnetic flux changes in the conductor (RRP 54/61) are expected to produce voltage spikes of the order of 1-2 V. These spikes, mostly observed at magnet currents up to 5-6 kA, can easily trigger a quench detection system. The new detection system has a current dependent threshold allowing high threshold at low currents, to avoid trips due to the voltage spikes, and low threshold at high magnet currents, to maintain peak temperatures below $380 \mathrm{~K}$. The new system is based on FPGA programmable modules built in the PXI platform working in addition to the existing quench management system in VME standard. Quench detection threshold can be set in 10 different current regions. Also the half-coil analog quench detection module of the VME system was modified to provide current dependent threshold settings.

The strain gauge readout system was upgraded in order to provide more accurate reading of low voltage signals from the LQS01 strain gauges, which are connected in a full-bridge circuit. The strain gauge system can accommodate up to a maximum of 64 gauges.

Power system grounding was also upgraded in order to provide better magnet safety and performance of the ground fault detection system. In the previous configuration the negative current bus was grounded through a $25-\mathrm{Ohm}$ current limiting resistor. The modified ground connection is symmetric with re- 


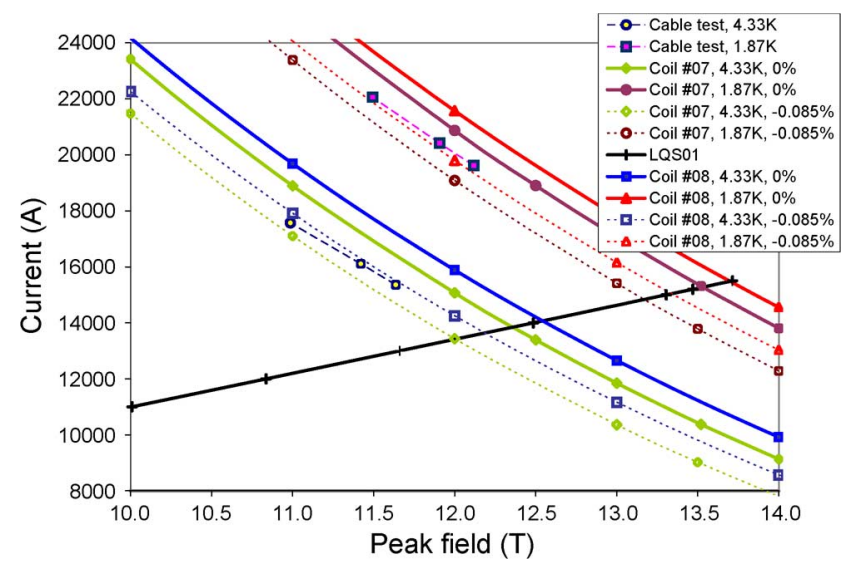

Fig. 3. Quench current recorded during Coil-\#08 cable tests when the beginning of the voltage rise was visible; and Coil-\#08 and Coil-\#07 critical current estimates (with and w/o additional thermal strain) based on measurement of extracted witness samples. The third number in the legend shows the additional strain used in the computation. Coil-\#08 cable measurements show a good agreement with the Ic estimates computed including $-0.085 \%$ additional strain. LQS01 short sample limit computation, presented in the text, is based on coil-\#07 critical current.

spect to power leads. It reduces peak coil to ground voltage by factor of 2 , and ground current through the fault by a factor of 10.

\section{CABLE TEST AND LQS01 SSL}

Two cable samples, cut from the cable spool used for LQ coil $\# 08$, were heat treated with coil \#08. The samples were subsequently assembled and impregnated at Fermilab into a stainless steel sample holder [13] designed for test at FRESCA (CERN cable test facility) [14]. The samples were tested at FRESCA in two thermal cycles from September 14 to October 6, 2009. During the test the samples were always oriented with the selffield, between the two cables, parallel to the FRESCA field. Training was performed at $4.3 \mathrm{~K}$ with $9.6 \mathrm{~T}$ background field. After a few training quenches the beginning of an exponential voltage rise could be seen in both cables at the same current, showing that the samples had reached the critical surface. Although the voltage rise reached the critical-current criteria only at $4.3 \mathrm{~K}$ with $9.9 \mathrm{~T}$ of background field, the quench current of other current ramps, which showed the beginning of the voltage rise, can be used to locate, with a small error, the critical surface (further analysis is in progress aiming at more precise estimates). These quench currents can be seen in Fig. 3 .

The expected critical current of these cables was computed by using strands extracted from the same cable spool (this cable was made of strands manufactured from a single billet), heat treated with these cable samples, and tested at $4.33 \mathrm{~K}$ on Ti-Al-V barrels. The strand test results included a self-field of 0.483 $\mathrm{T} / \mathrm{kA}$ [15]. For the cable test results a self-field of $0.11 \mathrm{~T} / \mathrm{kA}$ was used. A best fit of the strand results using the parameterization reported in [16] was performed and used to compute the cable critical current. The parameterization assumes an axial thermal strain of $-0.2 \%$ in the strand after cooldown on Ti-6Al-4V, and uses these parameters: $\mathrm{Ca} 1=48.61 \mathrm{~T}$; $\mathrm{Ca} 2=0 \mathrm{~T}$; $\varepsilon_{0, \mathrm{a}}=0.222 \% ; \operatorname{Bc} 2 \mathrm{~m}(0,0)=27.38 \mathrm{~T} ; \operatorname{Tcm}(0,0)=16.7 \mathrm{~K}$;
$\mathrm{C}=54461 \mathrm{AT}$. The discrepancy between the expected cable critical current and the quench currents in Fig. 3 is $\sim 12 \%$ at 4.3 $\mathrm{K}$ and $7.5 \%$ at $1.9 \mathrm{~K}$ (computed at the highest total field reached at each temperature). This difference may be caused by different strain conditions, and/or incorrect self-field adjustments. A fit of the cable test results at 4.3 and $1.9 \mathrm{~K}$ was performed by using the witness-strand parameterization and allowing a different strain in the cable. The best fit (shown in Fig. 3) was obtained by using an additional $-0.085 \%$ thermal strain in the cables (i.e. $-0.285 \%$ total). The difference between the thermal contraction during cool-down of the Ti-Al-V barrels, used for the strands, and the stainless-steel holder, used for the cables, is about $-0.11 \%$ and could explain this strain difference, in agreement with [17].

The short sample limit (SSL) of LQS01 was computed by using critical current measurement performed on strand samples extracted from the cable used for coil \#07 and heat treated with the same coil. These witness samples showed the lowest current among the LQS01-coil witness samples, likely because coil \#07 average temperature was $\sim 4^{\circ} \mathrm{C}$ below the $640^{\circ} \mathrm{C}$ target during the last step of the heat treatment. Following the procedure previously described, a best fit of the measurement at $4.3 \mathrm{~K}$ on Ti-Al-V barrels was performed including the strand self-field. $\operatorname{Tcm}(0,0)$ was set to $16.5 \mathrm{~K}$ (based on a fit of other coil-\#07 witness samples measured at 4.3 and $1.9 \mathrm{~K}$ on stainless steel barrels). The resulting parameterization was used to compute the critical current presented in Fig. 3. The LQS01 SSL is $13880 \mathrm{~A}$ at $4.33 \mathrm{~K}$, and $15313 \mathrm{~A}$ at $1.87 \mathrm{~K}$. Since the actual coil strain can hardly be predicted, the LQS01 SSL was computed also assuming the same strain of the cable samples tested at FRESCA. The results of this computation (13433 A at $4.33 \mathrm{~K}$ and $14845 \mathrm{~A}$ at $1.87 \mathrm{~K}$ ) can be used to see the sensitivity of the SSL to strain and to other possible causes of the discrepancy between strand and cable measurements.

\section{CONCLUSION}

LQS01, the first 3.7-m long quadrupole with $\mathrm{Nb}_{3} \mathrm{Sn}$ coils, has been assembled and is under preparation for test.

\section{ACKNOWLEDGMENT}

The authors thank J. Kerby (FNAL), A. Lietzke (LBNL, retired), G. de Rijk and E. Todesco (CERN) for participating in LQS01 Readiness Reviews and for the useful comments and recommendations.

\section{REFERENCES}

[1] P. Wanderer, "Overview for LARP Magnet R\&D," IEEE Trans. Appl. Supercond., vol. 19, no. 3, pp. 1208-1211, June 2009.

[2] J. F. Muratore et al., "Test results of LARP $3.6 \mathrm{~m} \mathrm{Nb}_{3} \mathrm{Sn}$ racetrack coils supported by full-length and segmented shell structures," IEEE Trans. Appl. Supercond., vol. 19, no. 3, pp. 1212-1216, June 2009.

[3] F. Nobrega et al., " $\mathrm{Nb}_{3} \mathrm{Sn}$ accelerator magnet technology scale-up using cos-theta dipole coils," IEEE Trans. App. Supercond., vol. 18, no. 2, pp. 273-276, June 2008.

[4] R. C. Bossert et al., "Fabrication and test of LARP technological quadrupole models of TQC series," IEEE Trans. Appl. Supercond., vol. 19, no. 3, pp. 1216-1230, June 2009.

[5] S. Caspi et al., "Test results of LARP Nb3Sn quadrupole magnets using a shell-based support structure (TQS)," IEEE Trans. Appl. Supercond., vol. 19, no. 3, pp. 1221-1225, June 2009. 
[6] H. Felice et al., "Test results of TQS03: A LARP shell-based Nb3Sn quadrupole using 108/127 conductor," J. Phys. Conf. Ser., submitted for publication.

[7] H. Felice et al., "Instrumentation and quench protection for LARP $\mathrm{Nb}_{3} \mathrm{Sn}$ magnets," IEEE Trans. Appl. Supercond., vol. 19, no. 3, pp. 2458-2462, June 2009.

[8] G. Ambrosio et al., Long Quadrupole Design Report [Online]. Available: https://dms.uslarp.org/MagnetRD/longquad/LQ_DR.pdf LARP report

[9] G. Ambrosio et al., "Development and coil fabrication for the LARP 3.7-m long $\mathrm{Nb}_{3} \mathrm{Sn}$ quadrupole," IEEE Trans. Appl. Supercond., vol. 19, no. 3, pp. 1231-1234, June 2009.

[10] P. Ferracin et al., "Fabrication and test of a $3.7 \mathrm{~m}$ long support structure for the LARP $\mathrm{Nb}_{3} \mathrm{Sn}$ quadrupole magnet LQS01," IEEE Trans. Appl. Supercond., vol. 19, no. 3, pp. 1106-1111, June 2009.

[11] P. Ferracin et al., "Assembly and loading of LQS01, a shell-based 3.7 $\mathrm{m}$ long $\mathrm{Nb}_{3} \mathrm{Sn}$ quadrupole magnet for LARP," IEEE Trans. Appl. Supercond., submitted for publication.
[12] M. J. Lamm et al., "A new facility to test superconducting accelerator magnets," in Proceedings of PAC97, pp. 3395-3397.

[13] G. Ambrosio et al., Design of a Sample Holder for $\mathrm{Nb}_{3} \mathrm{Sn}$ Cable Test at FRESCA Fermilab TD note, TD-04-022.

[14] A. P. Verweij, J. Genest, A. Knezovic, D. F. Leroy, J.-P. Marzolf, and L. R. Oberli, "1.9 K test facility for the reception of the superconducting cables for the LHC," in Proceedings ASC 1998, 1999.

[15] V. V. Kashikhin, Self-Field Description for Superconducting Wires FERMILAB-TM-2445-TD.

[16] A. Godeke, B. ten Haken, H. H. J. ten Kate, and D. C. Larbalestier, "A general scaling relation for the critical current density in $\mathrm{Nb}_{3} \mathrm{Sn}$," Supercond. Sci. Technol., vol. 19, pp. R100-R116, 2006.

[17] A. K. Ghosh, Effect of Barrel Material on the Measured Ic of RRP Nb3Sn Wires BNL Magnet Division Technical Note, \#MDN-657-39, 2008. 